\title{
Interim results of a clinical trial using oncolytic virotherapy in Kaposi's sarcoma-associated herpesvirus (KSHV)
} associated-Multicentric Castleman's Disease (MCD)

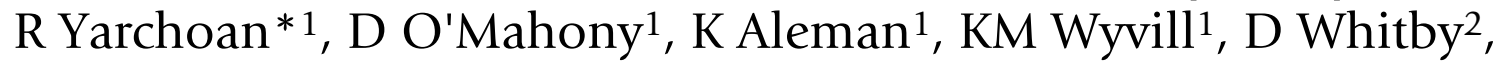 \\ W Bernstein ${ }^{1}$, S Pittaluga ${ }^{3}$, ES Jaffe ${ }^{3}$, G Tosato ${ }^{4}$, DA Davis ${ }^{1}$, SM Steinberg 5 and \\ RF Little ${ }^{1,6}$
}

\begin{abstract}
Address: ${ }^{1} \mathrm{HIV}$ and AIDS Malignancy Branch, Center for Cancer Research, National Cancer Institute, Bethesda, Maryland, USA, ${ }^{2}$ AIDS and Virus Cancer Program; National Cancer Institute, Frederick, Maryland, USA, ${ }^{3}$ Laboratory of Pathology, Cancer for Cancer Research, National Cancer Institute, Bethesda, Maryland, USA, ${ }^{4}$ Laboratory of Cellular Oncology, Cancer for Cancer Research, National Cancer Institute, Bethesda, Maryland, USA, ${ }^{5}$ Biostatistics and Data Management Section, Cancer for Cancer Research, National Cancer Institute, Bethesda, Maryland, USA and ${ }^{6} \mathrm{Clinical}$ Investigations Branch, Cancer Therapy Evaluation Program; National Cancer Institute, Bethesda, Maryland, USA

* Corresponding author
\end{abstract}

from I I th International Conference on Malignancies in AIDS and Other Acquired Immunodeficiencies (ICMAOI): Basic, Epidemiologic, and Clinical Research

Bethesda, MD, USA. 6-7 October 2008

Published: 17 June 2009

Infectious Agents and Cancer 2009, 4(Suppl 2):O20 doi:I0.1 I86/I750-9378-4-S2-O20

This abstract is available from: http://www.infectagentscancer.com/content/4/S2/O20

(C) 2009 Yarchoan et al; licensee BioMed Central Ltd.

Kaposi's sarcoma-associated herpesvirus (KSHV), also called human herpesvirus-8 (HHV-8), is an oncogenic gammaherpesvirus associated with Kaposi's sarcoma (KS), primary effusion lymphoma (PEL), and a form of MCD. KSHV-associated MCD (KSHV-MCD) is a rare Bcell lymphoproliferative disease almost universally found in association with HIV infection that is characterized by a recurrent systemic syndrome of fatigue, fevers, cytopenias, elevated serum C-reactive protein (CRP), and lytic KSHV replication with production of a virally-encoded interleukin-6 (vIL-6). There is no standard therapy for KSHV-MCD although there are reports of patients responding to a variety of agents including interferon alpha, cytotoxic chemotherapy, rituximab or ganciclovir. Overall, the prognosis is poor (median survival 14 months). KSHV open reading frames (ORF) 21 and 36 respectively have the ability to phosphorylate zidovudine and ganciclovir to toxic triphosphate moieties. We found that when these lytic genes are activated in PEL cell lines, as by hypoxia, the cells can be killed by concentrations of these drugs that are clinically attainable (Cancer Res 2007; 67:7003-7010).
We have explored the translation of these observations to the clinic in MCD, taking advantage of lytic KSHV replication already present in the tumor cells. Ten patients with symptomatic biopsy-confirmed KSHV-MCD were treated with high dose oral zidovudine (HDAZT), 600 mg every 6 hours, and valganciclovir (VGCV), $900 \mathrm{mg}$ every 12 hours; the protocol was approved by the NCI Institutional Review Board and all patients gave informed consent. Treatment length of the first cycle was dependent on response, and ranged from 7-21 days. Subsequent cycle length was 21 days with treatment administered during the first 7 days. Treatment was stopped when patients achieved a complete response (CR) or plateau in response. Patient characteristics were: median age 40 (range 33-56); ECOG PS 2 (1-3); median enrollment CD4 count 189 (range 19-1319 UL); median HIV viral load $<50$ copies $/ \mathrm{ml}^{3}$ plasma (range $<50$ to 27,500 ). All patients were on combination antiretroviral therapy; this was adjusted during the time patients were on AZT. Eight patients had a history of KS. Median duration of MCD was 3.5 months (range 0.5-45 months); seven patients had received at least one prior therapy for MCD (range 1-6). All had MCD-related constitutional symptoms and CRP 
above $0.8 \mathrm{mg} / \mathrm{dl}$ (median 13.1, range $1.06-38.7 \mathrm{mg} / \mathrm{dl}$ ) at treatment initiation. A total of 112 cycles have been administered to date, with a median of 10 (range 3-29) cycles per patient.

Nine of 10 patients had documented improvement in constitutional symptoms, C-reactive protein levels or cytopenias. Five patients achieved an objective response as defined by the protocol (two CR and three partial remissions). The median survival has not been reached; the 12 month probability of survival is 70 percent, and patients remain alive from 12.5 to 32 months. The median PFS is 5.4 months; two patients have not yet progressed after 15.5 and 27 months on study. Seven patients remain alive. Treatment was well tolerated; toxicity included two patients with fatigue (grade [gr] 3), one with nausea (gr3), one with transaminitis (gr3) and one with insomnia (gr3). Grade 3 or 4 hematologic toxicity not attributable to disease was seen in only two patients. Two patients developed KSHV-associated lymphoma. Three infectious events occurred, a staphylococcal skin abscess, streptococcal meningitis and a streptococcal pneumonia. There were no neutropenia-associated infections. In summary, this preliminary data suggests that the combination of HDAZT and VGCV is well tolerated and has activity in patients with KSHV-MCD. Accrual continues.

\section{Acknowledgements}

This research was supported by the Intramural Research Program of the $\mathrm{NIH}, \mathrm{NCl}$.
Publish with Biomed Central and every scientist can read your work free of charge

"BioMed Central will be the most significant development for disseminating the results of biomedical research in our lifetime. " Sir Paul Nurse, Cancer Research UK

Your research papers will be:

- available free of charge to the entire biomedical community

- peer reviewed and published immediately upon acceptance

- cited in PubMed and archived on PubMed Central

- yours - you keep the copyright

Submit your manuscript here:

http://www.biomedcentral.com/info/publishing_adv.asp 